\title{
Once the Earth Stood Sill (Part II): Mental Health Services in Post-Quake Haiti
}

\section{By Conner Gorry MA}

Natural disasters of the magnitude of the January 2010 earthquake in Haiti rend societies, exposing social inequities and laying bare weak disaster mitigation strategies. These tragic events not only test the limits of communities, families, and individuals, but also reveal the strength and mettle of survivors. Struggling to recover and rebuild, young and old stand as daily testament to human resilience. For participants in a mental health program led by Cuban health professionals in Haiti, this resilience has-at times, if only momentarily-translated into smiles, laughter, and hope.

The mental health program is an innovation within Cuba's Henry Reeve Team of Medical Specialists in Disasters and Epidemics, which has served in nearly a dozen disaster-stricken countries from Pakistan to Peru since 2005.[1] Less than 24 hours after the Haiti quake, the Henry Reeve contingent arrived to join over 300 Cuban health professionals already engaged in long-term service staffing public health facilities throughout the country under Cuba's Comprehensive Health Program (CHP).[2] Two weeks later, a group of four psychologists, four psychiatrists, and two pediatric psychiatrists-all specially trained in mental health for disaster response and recovery-arrived in Port-auPrince to head the pilot program. By the time they withdrew on April 29, they had trained 350 Haitian mental health promoters and benefited over 150,000 Haitian youth using a methodology developed in Cuba.

\section{The Chernobyl Legacy}

Cuba's mental health and disaster strategy traces its origins to the comprehensive treatment and rehabilitation program begun in 1990 for children affected by the Chernobyl nuclear disaster.[3] In addition to treating medical conditions including hyperthyroidism, various cancers, and vitiligo, the multidisciplinary team at Tarará Hospital in eastern Havana (where the program is headquartered) developed a mental health component, emphasizing cultural and recreational activities designed to facilitate the young patients' psychological rehabilitation.

"Post-traumatic stress was a major effect of that disaster. Many of these children have undergone numerous, long-term medical treatments, while others have physical deformities," Dr Julio Medina, director of the hospital, told MEDICC Review. "These activities-trips to the movies and museums, playing on the beach, and days at the amusement park - go a long way toward helping these children recover psychologically."

The experience treating Chernobyl children evolved into a formal mental health program in 2001, coordinated by the Havanabased Latin American Center for Disaster Medicine (CLAMED). Since then, CLAMED has begun offering a master's degree in disaster-related mental health and designed a mental health strategy incorporated into national hurricane preparedness and

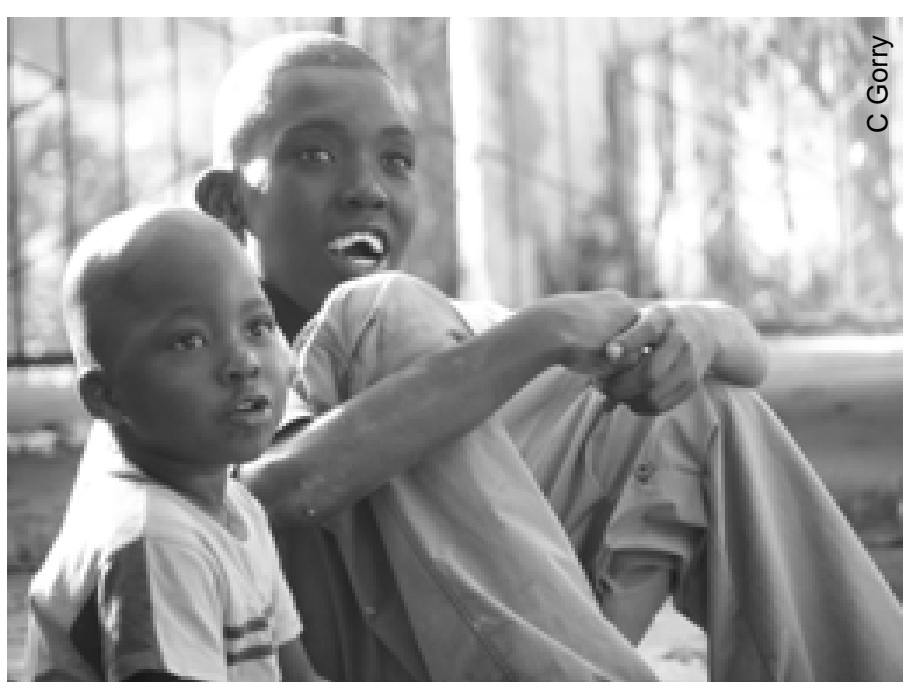

disaster mitigation efforts since 2006. Two years later, this strategy was formally adopted by the Ministry of Public Health as the Guidelines for Mental Health and Disasters in Cuba.

"We take a holistic approach-we don't just treat the medical or psycho-pathological effects of disaster," Dr Alexis Lorenzo, Director of Services at Tarará Hospital and Coordinator of CLAMED's Mental Health Group told MEDICC Review. "We try to understand each person within a broader context, taking into account all the factors in their lives [that contribute to their mental health]. I think we learned that from the Chernobyl children and that's the experience we took to Haiti," the psychologist explained.

The Cuban methodology is based on two fundamental principles:

1. The collective, historical memory of the disaster-stricken area is respected and integrated into the mental health response, taking into account popular knowledge and local beliefs, religious principles, personal experiences, and academic research.

2. Every disaster and every context is different. In designing a program for a specific context, the mental health team relies on knowledge-sharing among actors at all levels-local, regional, and international-and across sectors and mental health disciplines.

The program emphasizes individuals' capacity to act as agents of change and involves training local stakeholders to nurture protective factors that help foster resiliency and mitigate the negative impact of future disasters.[4]

\section{Training and Outreach in Haiti}

Within hours of receiving first reports of the devastation in Haiti, CLAMED specialists began amassing documents, preparing background materials, and formulating a needs assessment. Coincidentally, the Mental Health Group had recently compiled 
a special issue of CLAMED's global disaster bulletin dedicated to mental health in Haiti.

Upon arrival in Port-au-Prince, the 10-member mental health team headed by Dr Lorenzo began training members of the Henry Reeve contingent. Workshops on mental health and disasters were held first with its coordinators, then with administrators of each field hospital in the disaster area, who then trained doctors and other health professionals under their supervision. These included over 700 doctors and medical students educated at $\mathrm{Cu}$ ba's Latin American Medical School (ELAM) - the first time the Henry Reeve contingent has incorporated such a multinational group. Program organizers estimate $85 \%$ of the contingent participated in the training.

To promote sustainability and maximize the program's multiplier effect, the mental health team also held workshops with local leaders, community members, local NGO staff, and other stakeholders to carry forward the program once the Henry Reeve contingent withdrew. Outreach to identify and involve local counterparts was facilitated by the network of Haitian colleagues linked to the CHP over the last 12 years, as well as relationships built with Haitian health authorities over that time.

"Since individuals are ultimately responsible for their own mental health and serve as multipliers for their community, part of our objective was to provide effective training for them," Dr Lorenzo explained. "The more prepared a person is, the more they can help. Our goal was to provide people affected by the earthquake with psychological and social resources to be able to start rebuilding their lives. In post-disaster situations, water, food, housing, and medicine are of primary importance, but these things alone will not enable a person to reconstruct their life."

Through the training component, 350 mental health promoters learned support, self-help, and self-esteem awareness techniques aimed at helping survivors feel useful and effective in confronting their post-quake reality. Just as importantly, Henry Reeve members have said participating in the mental health activities also helped improve their own mental state.

\section{Focus on Children and Youth}

After identifying communities in need, consulting with their leaders and receiving consent to proceed, the Henry Reeve contingent carried out health and epidemiological assessments, including mental health assessments of children and teens. The most common conditions identified by the team included anxiety, fear, stress and depression.

Based on these findings and considering the enormous destruction and sheer number of Haitians directly affected, the mental health team, together with Haitian mental health specialists and the Haitian ministries of health, youth, and education, decided that a program for children and youth would be most effective and have the greatest multiplier effect. While children and adolescents are considered among the most vulnerable groups in disaster situations due to health conditions, interruptions in education and recreational activities, and difficulties confronting death, they are also generally more flexible than adults and more receptive to postdisaster rehabilitation and education efforts.[4]

On February 5, at the Croix des Bouquets field hospital near the capital, the Cuban-led team held its first activity designed to mitigate the psycho-social effects of the earthquake. "This is one of my most vivid, emotional memories from Haiti," Dr Lorenzo said. "The activity was held for about 300 kids and as it was wrapping up, a mother arrived with her three children-a teenage boy, a young girl of about seven, and a baby. I set the older ones to drawing with markers and paper we provided for all the kids and took her baby in my arms. She looked surprised at such affection. When her older kids finished, drawings in hand, she gave me a hug and said, 'People in the tent city are saying the Cubans are holding an activity for kids where they're distributing food and water. But seeing my children smile, like they haven't smiled in a long time, is so much more than food or water. It just doesn't compare."'

Similar activities were held the same day each week in the five field hospitals and five permanent hospitals in the emergency area in and around Port-au-Prince staffed by the Henry Reeve contingent. These activities are continuing, complemented by periodic health and book fairs designed to reach the most vulnerable and remote quake-affected communities. The specifics of each day-long fair are tailored to the needs for medicines and specialized care identified in the community assessments, and have included everything from psychiatric services for orphans to physical therapy for amputees.

Providing a role for children and youth in the common effort to return to "normal" is an important mechanism in confronting collective trauma. Thus, medical consultations are followed by the

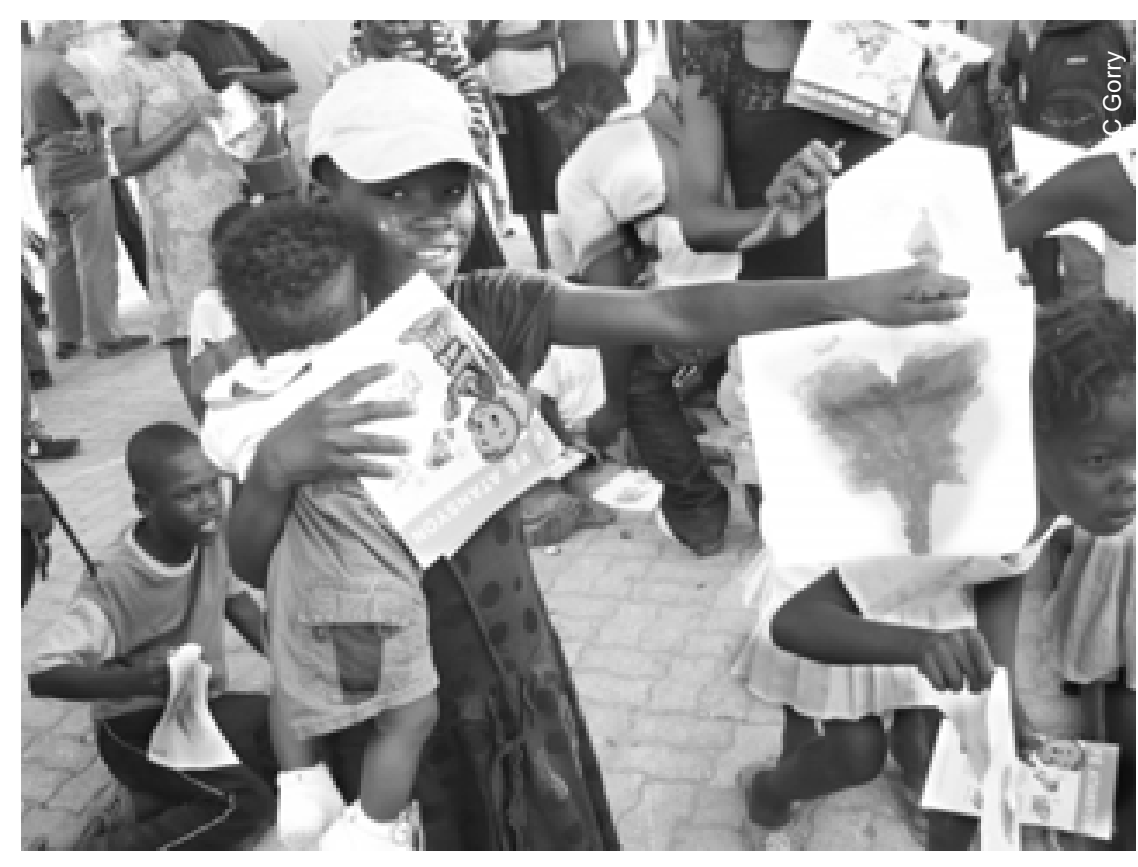

“...children again, one hundred percent." 
mental health portion of the fair, with group activities and distribution of children's books in Creole. "Learning and reading are protective factors. When children read stories to each other, when they realize they can do something for themselves and become protagonists in their own future, they are more likely to become multipliers and change agents in their families and communities," explained Dr Lorenzo. Between February 5 and April 29, the Henry Reeve contingent distributed seven titles in Creole, totaling over 80,000 books, and the Cuban-led medical teams continue to make follow-up visits to these communities.

The difficulties related to translation-especially in the area of mental health-cannot be overstated. While 5th-year Haitian medical students at Cuba's Latin American Medical School assisted the Henry Reeve contingent as facilitators and translators, the overwhelming demand for health services in post-quake Haiti meant that non-Creole-speaking doctors sometimes had to fend for themselves. "Translation has been a big challenge, but I developed some simple call-and-response games to get them involved," child psychiatrist Francisco Toledo, serving in the Carre Foure field hospital, told MEDICC Review. Games and singing are common techniques used by the mental health team to break down cultural and language barriers. Art is another.

\section{Martha Machado Artists Brigade}

Another first for Cuban disaster response was incorporation of the Martha Machado Artists Brigade into the Henry Reeve contingent's mental health activities. The brigade of painters, musicians, clowns, magicians, stilt-walkers, and puppeteers was founded by Cuban artist Alexis Leyva Machado (Kcho) after a trio of hurricanes hit Cuba in 2008.[5] Using art, music, dance, and play, the Brigade helped children in the most heavily affected Cuban provinces express their fears in a fun, joyful atmosphere.

Such art and play have shown positive results in alleviating suffering and mitigating the psychological effects of disasters-especially for children, who are generally less able to express their emotions verbally following traumatic events. The importance of art as a pro-active, palliative tool was reinforced by the Brigade's experience in post-hurricane Cuba and emphasized during their activities in Haiti.

Kcho and his troupe arrived in March and toured the region hardest hit by the earthquake, performing almost daily in a different location, from field hospitals to orphanages. During activities featuring circus performers, tap dancers, and magicians, the Brigade developed an enchanting and creative space for young and old alike.

"At first, the kids are quiet, dejected. But slowly they draw closer and begin to participate. If I showed you a photo of these kids laughing and dancing, you would never guess they were earthquake survivors. At these activities, they became children again, one hundred percent," Dr Lorenzo observed.

The artists also provided art supplies and helped the children explore their feelings through drawing, painting and collage, often painting alongside them. "Haitian kids have amazing creativity and what they make is incredible," commented Ernesto Rancaño, a founding member of the Brigade and one of
Cuba's most accomplished contemporary artists. "We'll show them a couple of simple techniques and they'll just run with it. There's a lot of talent here and when they're painting, they're in another world."

Part of the Martha Machado Brigade's commitment to Haiti is sharing that creativity and talent with as many people as possible: the Cuban artists have installed 25 of their paintings in public hospitals around the country, along with some 100 works by Haitian children and another 15 made by Cuban children during the Brigade's 2008 tour around the island. The Brigade also worked actively with teachers from Haiti's national art school to help develop and apply this methodology throughout the country.

\section{Tapping Mental Health Reserves for the Future}

Haitians continue to experience damaging psycho-social effects caused by the January earthquake. According to the mental health program specialists, these are normal reactions to abnormal circumstances. But over six months have elapsed, and disaster and relief agencies, together with the Haitian government, are still struggling to resolve food, shelter, and water shortages amidst threats from a new hurricane season. These persistent problems, compounded by displaced Haitians' wretched living conditions, mean survivors are constantly reminded of the original event-one of the primary factors contributing to the development of post-traumatic stress disorder. Without proper protective factors and support, recovery from the trauma may be seriously compromised, with dire outcomes for survivors' mental and emotional well-being.

Although some 150,000 Haitian children and adolescents benefited from the Cuban mental health program between February and April, they are just a small percentage of the population suffering psychological effects of the earthquake. Each week, communities throughout the country participate in group activities developed by the Henry Reeve contingent and now led by doctors from Cuba's Comprehensive Health Program in Haiti. Additionally, children continue to receive age-appropriate books in Creole at over 20 hospitals staffed by these health professionals.

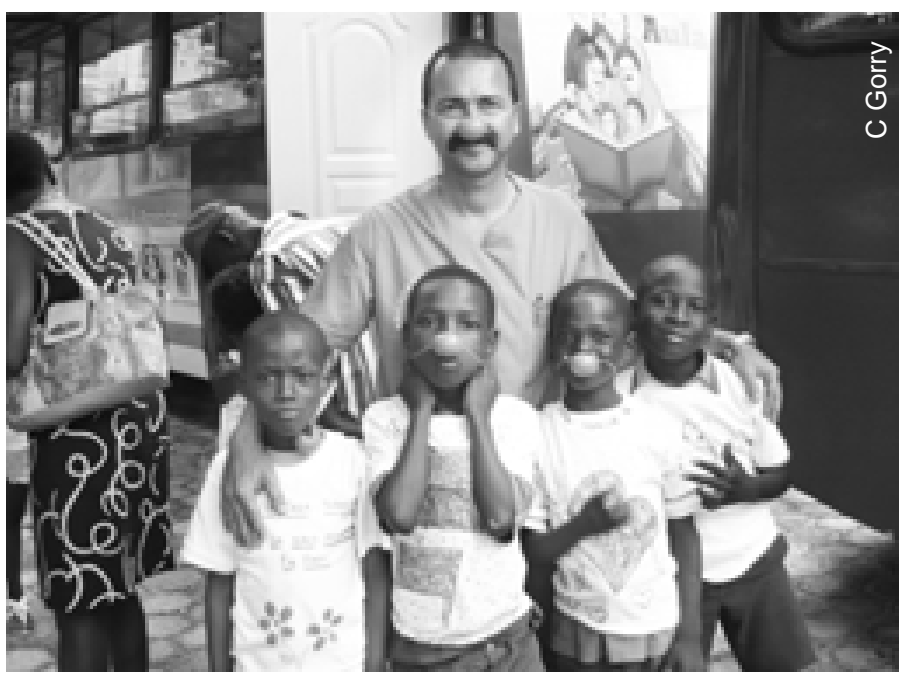

Dr Lorenzo with Haitian youngsters after t-shirt painting, Port-au-Prince 
It is also hoped that the training component of the mental health program will have the desired multiplier effect, increasing its positive impact. "We're encouraged, especially by the response in the communities where we've worked," Dr Lorenzo said. "Each smile, hug, and brief moment of happiness proves that although they are deeply affected by the quake, Haitians are not victims but people with many psychological and social resources." Channeling such resources is key to constructing a safe, sustainable future for Haiti's children. W-

\section{References \& Notes}

1. For more information about the Henry Reeve Medical Team, see Cuban Health Cooperation Turns 45 and Cuba's Man in Sichuan China: José Rodríguez, MD, in MEDICC Review, Summer 2008, Vol 10, No 3, available from: http://www.medicc. $\mathrm{org} /$ mediccreview/index. php?issue=3\&id=16\&a=vahtml
2. The Comprehensive Health Program was established in 1998 after Hurricanes Mitch and Georges ripped through Central America and the Caribbean, exposing brutal health disparities among the region's poor. By 2008, Cuba had signed accords with 37 countries, under which Cuban health professionals provide health care in poor communities. In Haiti, over 3,000 Cuban health professionals and technicians have staffed public health facilities in two-year rotations. Under the $\mathrm{CHP}$, many of these countries, including Haiti, have also taken advantage of $\mathrm{Cu}$ ban scholarships to the Latin American Medical School.

3. This program continues today and has treated nearly 25,000 children from the Ukraine, Belarus, and Russia free of charge since its founding.

4. Protective factors are defined as conditions or environments that encourage the development of individuals and groups, while reducing the effects of unfavorable conditions: in other words, the opposite of risk factors. See Martínez C. Importance of Protective Factors for the Mental Health of Children and Adolescents in Emergencies and Disasters. MEDICC Review, December 2004, Vol 6, No 3, available from: http://www.medicc.org/publications/medicc_review/1204/pages/cuban_medical literature.html

5. The Brigade was named for Kcho's mother who sheltered neighbors after the 2008 hurricanes devastated the Isle of Youth Special Municipality. Along with Pinar del Río, Camagüey, Las Tunas, and Holguín provinces, the Isle of Youth was among the hardest hit by the storms.

This report is the result of Senior Editor Conner Gorry's month-long assignment covering the Henry Reeve Contingent in and around Port-au-Prince. For more, see Part I of the series Once the Earth Stood Still on rebuilding the Haitian health system in the Spring 2010 issue of MEDICC Review, and Field Notes from MEDICC: http://mediccglobal.wordpress.com.

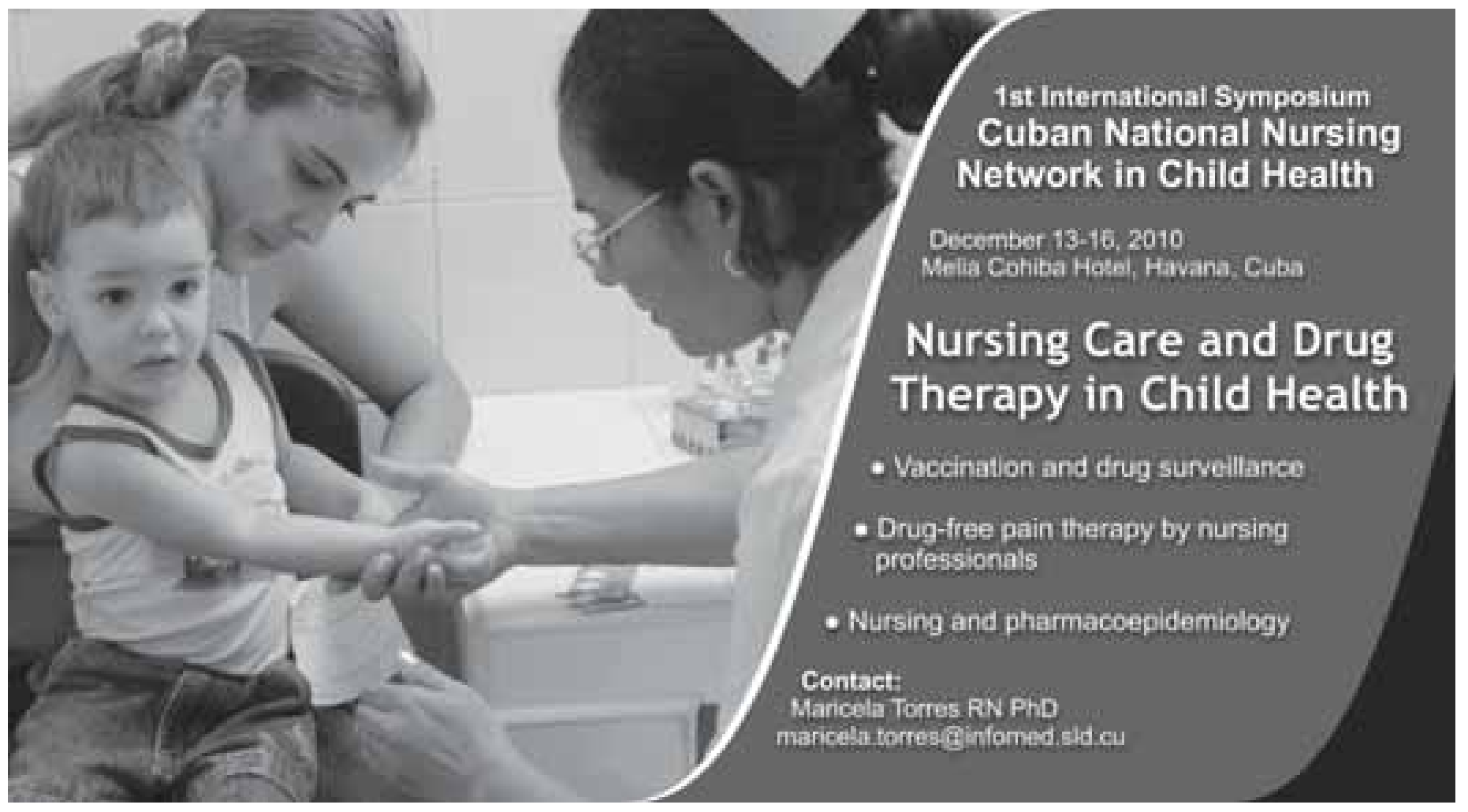

